NBER WORKING PAPER SERIES

SUCCESSFUL ADJUSTMENT IN A MULTI-SECTORAL ECONOMY

Joshua Aizenman

Working Paper No. 2202

NATIONAL BUREAU OF ECONOMIC RESEARCH 1050 Massachusetts Avenue

Cambridge, MA 02138

April 1987

I would like to thank Ruth Klinov for discussions that motivated this paper. All errors, however, are mine. The research reported here is part of the NBER's research program in International Studies. Any opinions expressed are those of the author and not those of the National Bureau of Economic Research. 


\section{Successful Adjustment in a Multi-Sectoral Economy}

\section{$\underline{\text { ABSTRACT }}$}

This study analyzes the adjustment to a fiscal reform in a dependent economy. It evaluates the economic factors that are relevant for making the choice between a cut in employment versus a cut in wages as a means of reducing the fiscal wage bill. We demonstrate that in the presence of costly short-run mobility of labor there is a natural advantage to a wage policy over employment policy. Fiscal deficits can be dealt with successfully by a wage policy and with the corresponding adjustment in government demand. These policies may have only marginal consequences on production of traded goods in the short run in the presence of costs of adjustment. Over time the gain in the production of traded goods is determined by the credibility of the fiscal reform. It is shown that the absence of credibility may have major consequences on the adjustment, because it will depress the magnitude of the private investment associated with the fiscal reform.

Joshua Aizenman

GSB, University of Chicago

1101 E. 58 st.

Chicago, IL 60637

(312) 7027260 


\section{INTRODUCTION AND SUMMARY}

Countries running non-sustainable fiscal deficits are facing an important policy choice regarding the proper mix of fiscal reforms. An important purpose of these reforms is to reduce the public wage bill. This can be done by applying a mixture of various policies, each putting different emphasis on a drop in public employment versus a drop in real wages in the public sector. Recent experience in various countries (for example Chile, Israel and Argentina) has demonstrated that indeed countries differ in the importance they attach to employment versus wage policies. This observation is raising important policy questions regarding the economic factors determining the desirability of each policy.

The purpose of this paper is to evaluate the economic factors that are relevant for making the choice between a cut in employment versus a cut in wages as a mean of reducing the fiscal wage bill. This question is another example of the problem of using quantity versus price instruments in the implementation of policies. We start by reviewing the experience of countries that have adopted different strategies. In section 2 we construct a simple model to evaluate the economic factors that are relevant for making the choice between a cut in employment versus a cut in wages as a means of reducing the public sector wage bill. We assume that mobility of labor is costly in the shortrun, due to time dependent retooling costs. We demonstrate that there is a natural advantage to wage policy over employment policy. The key factor generating this result is that even with flexible wages there may be limits to the feasible short-run reallocation of labor from the public to the private sector. Whenever there is uncertainty regarding the feasible reallocation, a cut 
in wages cannot generate unemployment, but a policy targeting a drop in public sector employment may result in unemployment. A wage policy can be applied to achieve any feasible efficient adjustment in the short-run, whereas an employment policy can lead to inefficient outcomes. Consequently, there is a natural comparative advantage to wage over employment policy. In section 3 we study the role of the credibility of the fiscal reform. It is shown that the absence of credibility has major consequences on the adjustment, because it will depress the magnitude of the private investment associated with the fiscal reform.

It would be useful to start our analysis by reviewing some recent examples of fiscal reform. This will allow us to identify several of the factors that play a role in the adjustment process. We do this by describing the fiscal reforms in Chile in 1975, and in Israel in 1985. Obviously, any cross country comparison is relatively crude and in the absence of full decomposition of the factors accounting for different adjustments one should not derive policy prescriptions from it ${ }^{1}$.

The 1975 fiscal reform in Chile can be described as a quantity oriented policy ${ }^{2}$. It involved a major reduction in government employment, by about 100,000 workers (about $2.4 \%$ of the total labor force). Interestingly, the real

1. At best, this can be done with the help of a conceptual model that attempts to explain the adjustment process. In our case this cavity is magnified by the fact that the fiscal stabilization of 1975 in Chile occurred simultaneously with a major adverse external real shock (a drop in the price of copper) whereas the fiscal stabilization of 1985 in Israel occurred against a background of favorable external shocks (the drop in the price of energy and the decline of the dollar). Furthermore, the fiscal reform in Israel is only at its first stage of implementation, and we lack the benefit of hindsight.

2. For a useful analysis of the Chilean experience, see Foxley (1982), Edwards (1984), Corbo (1985), Edwards (1985) and the references there. 
wage did not drop, and in fact it went up significantly ${ }^{3}$. The fiscal reform (with the supplementary policies) was successful in accounting for a drastic reduction in the fiscal deficit (from about $10.5 \%$ in 1974 to about $2.6 \%$ in 1975). It occurred at a time when other structural changes (such as tariffs liberalization) and external real shocks were affecting the economy. The combined effects of these shocks on the unemployment was unfavorable, and Chile experienced a major increase in open unemployment 4 . Figure 1 plots the evolution of public employment (in thousands of workers), real wages and public sector real wage bill during 1974 and $1978 .^{5}$ Note that despite the deep cut in public sector employment between 1974 and 1978 (by 20\%), the public real wage bill went up by more than 10\%. This observation is consistent with the interpretation that the policy had given greater weight to employment and a lower weight to wage cuts in the public sector.

The 1985 fiscal stabilization program in Israel has given greater emphasis to price (wage) policies ${ }^{6}$. It resulted in a major drop in real wages in

3. By about $6 \%$ from 1974 to 1975 , and by about $15 \%$ from 1975 to 1976 (see Table 3, Edwards (1985)).

4. The unemployment figures are complicated by the presence of minimum employment programs originated by the public sector. For further analysis of these issues see Edwards (1984) and Edwards (1985).

5. Total public sector employment in these years was 360 and 293 thousand workers (taken from Foxley (1982), Table 6). Public sector employment fell nearly 20\% between 1974 and 1978. With regard to 1973 , public employment dropped 25\% and represented a decrease of 100,000 workers. The real wage index for 1974 and 1978 was 60 , and 83 , respectively (measured relative to 1970, see Edwards (1985). Table 3). The approximation for the public sector real wage bill in Figure 1 is obtained by combining the information regarding real wage and public employment reported above.

6. For recent analysis of the Israeli stabilization see Bruno (1986), Dornbusch and Fischer (1986), Liviatan (1986) and Blejer and Liviatan (1986). 
Figure 1

INDEX AT 1974: 100

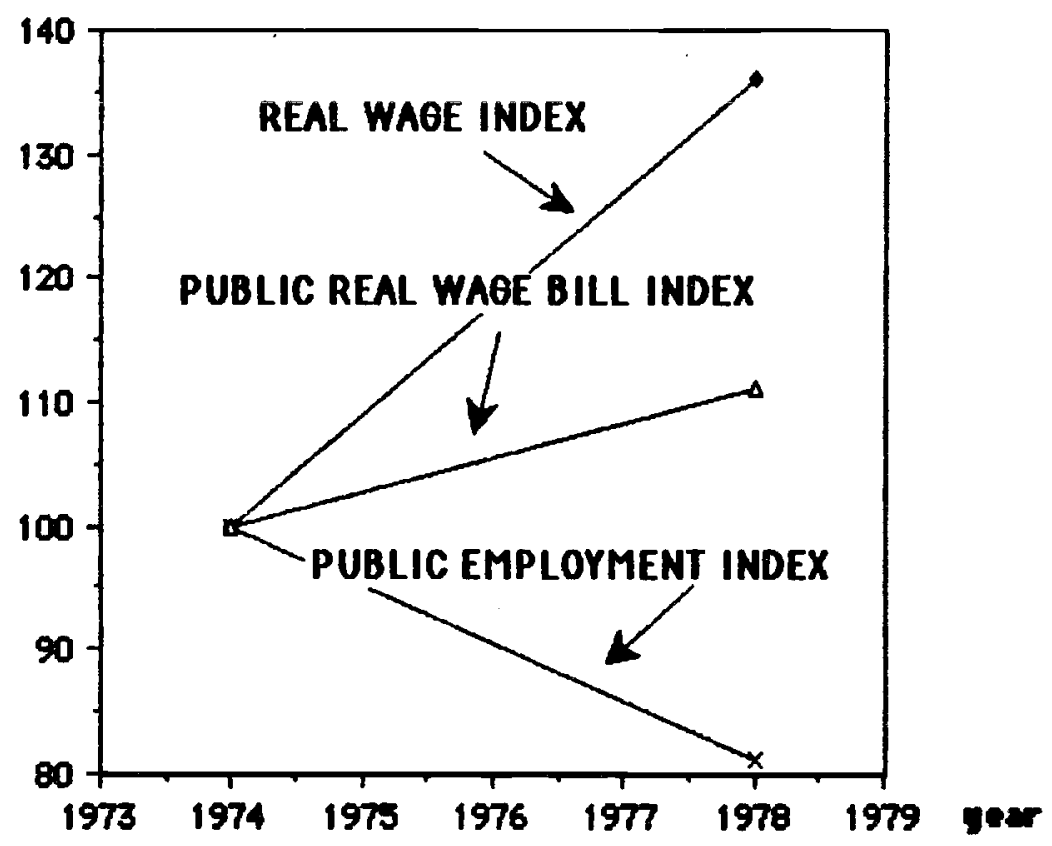


the public sector and a smaller reduction in real wages in the business sector. Figure 2 describes the time path of real wages in the two sectors during the first phase of the program ${ }^{7}$. The discrepancy between the wage path in each sector is related to the key role played by the public sector as a major employer in Israel, and the fact that a major component of the program has been an attempt to reduce real wages in the public sector in order to improve the competitiveness of the business sector (as well as to reduce the fiscal wage bill) $)^{8}$. The stabilization program has been (so far) successful in the reduction of the fiscal deficit with only marginal reduction in public employment ${ }^{9}$.

The above comparison should not be pushed too far (see footnote 1). It suggests, however, that there is a real policy choice to be made in an attempt to reduce a fiscal deficit. While in the long-run the distinction between wage versus employment policies in the fiscal sector may be not relevant, it may have major consequences regarding the short-run adjustment (and thereby regarding the attainment of the long-run). To clarify some of these issues it is constructive to turn to a simplified model of the adjustment process.

7. The base year for the index is 1980 . The information is taken from Bruno (1986), Table 5.

8. For a discussion on the role of the public sector in the Israeli labor market see Ben-Porath (1986) and Klinov (1986).

9. The stabilization plan also called for a cut in public sector employment of about 10,000 workers (which is equivalent to less than $1 \%$ of the total labor force). So far there is only limited (and conflicting) information regarding the implementation of this part of the program. The fiscal deficit (revenue minus domestic expenditure) has dropped from $8 \%$ (in 1984) to $1 \%$ (in 1985), and so far there have been only minor output effects. An open question is the willingness and the ability of the economic and political system in Israel to adhere to the new policy. 


\section{FIGURE 2}

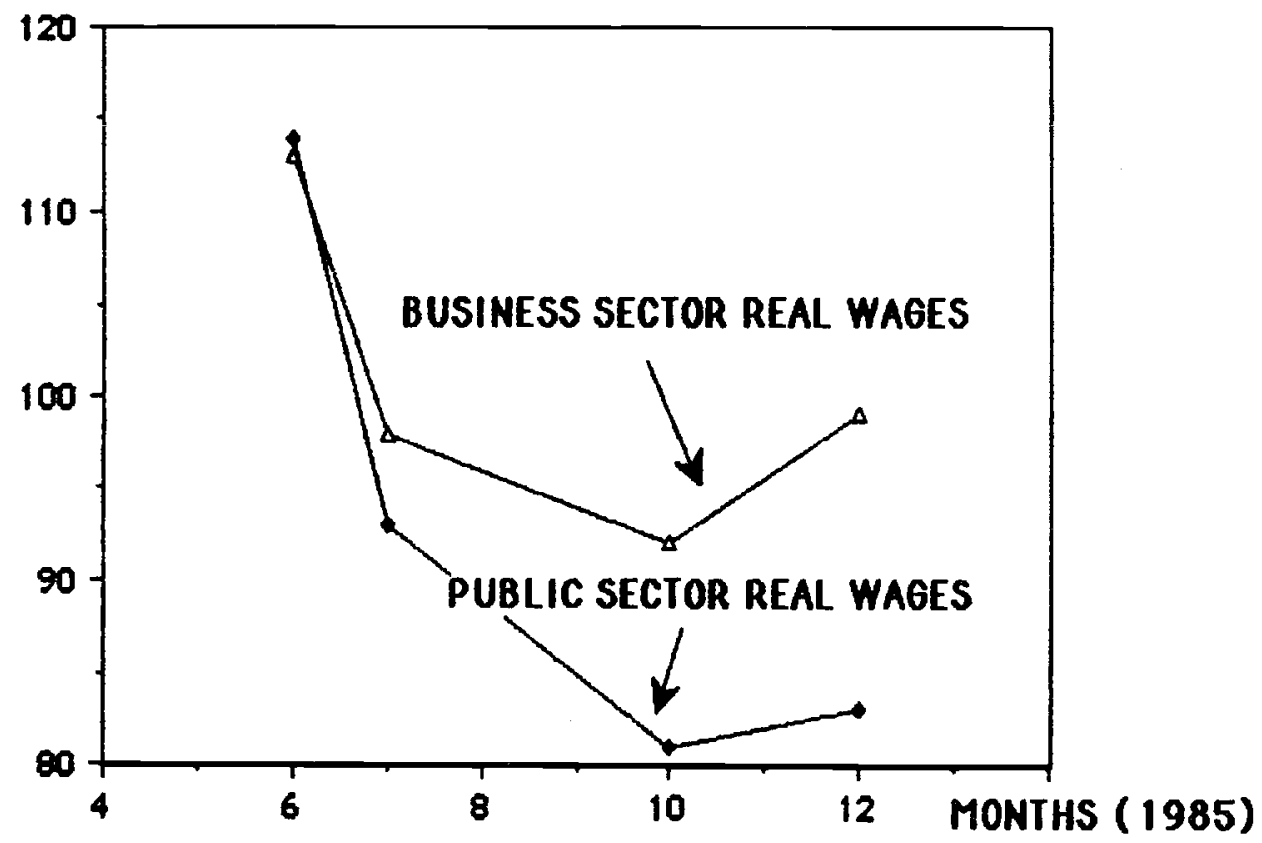




\section{THE MODEL}

In this section we outline the building blocks of the model. These bullding blocks contain a specification of the supply of output and the equilibrium in goods, labor and the capital market. We would like to design a simple model that will reflect two key characteristics of a dependent economy with an active public sector. First, in a typical dependent economy the size of the public sector has a major influence on the price of non-traded goods and wages, and the public sector is intensive in the provision of non-traded services. Second, while in the long-run the return on productive capital tends to be tied to world returns (due to the possibility of capital flight and due to foreign investment), in the short and intermediate runs fiscal policy has potent impacts on returns to productive capital.

\subsection{THE LONG -RUN EQUILIBRIUM}

Consider a two sectorial economy, producing traded and non-traded goods. The traded sector is capital intensive relative to the non-traded sector. For simplicity of exposition we assume that production in the non-traded sector follows a Ricardian technology:

$$
N=L_{n}
$$

where $L_{n}$ is the labor employed in the non-traded sector. Output in the traded sector is produced according to the following Cobb-Douglas production function: 
(2)

$$
Z=\left(L_{z}\right)^{B}(K)^{1-B} \quad ; \quad 0<B<1 .
$$

where $Z$ is the output of traded goods, $L_{2}$ is the labor employed in the traded sector, and $\mathrm{K}$ stands for the stock of capital. We normalize the prices of traded goods to one, and we denote the price on non-traded goods (which is also the relative price of non-traded to traded goods) by $P$.

We simplify the exposition by assuming that the only source of demand for non-traded goods is the government, which spends a constant share g out of the GNP on non-traded goods 10 . Thus, the demand for non-traded goods is:

$$
N_{d}=g[P N+Z] / P
$$

where the term in the bracket is the GNP (measured in terms of traded-goods). The aggregate supply of labor is fixed at $\bar{L}$, and equilibrium in the labor market implies that

$$
\text { (4) } \bar{L}=L_{z}+L_{n}
$$

As a consequence of the recent experience of various countries with capital flight, we assume that the private sector can invest abroad in assets

10. This assumption allows us to abstract from considerations related to the finance of the fiscal activity. Adding a private sector demand for nontraded goods will complicate the analysis without affecting the key results (the complication stems from the possible linkages between fiscal deficits, capital inflows and the private demand for non-traded goods). 
offering a risk-free interest rate (denominated in terms of traded goods) ${ }^{11}$. While country risk considerations may imply that there is no marginal investment by forelgners, the assumption regarding the presence of capital flight implies that domestic residents will invest in domestic productive capital such as to equate the yield on domestic capital to the external risk free yield:

(5) $\rho^{*}=M P_{k}$

where $\rho^{*}$ is the exogenously risk-free foreign return, and $M P_{k}$ is the marginal product of capital in the traded goods sector.

The long-run equllibrium is characterized by perfect labor mobility and accumulation of capital to satisfy equation (5). We assume the absence of systematic risk in the long-run. Notice that equation (1) implies that in a competitive labor market the wage $(W)$ is given by

(B) $w=p$

Competitive equilibrium in the traded-sector is characterized by the requirement that the rewards of inputs equal the value of the marginal product:

(7) $\rho^{*}=M P_{k}=(1-\beta) R^{-\beta}$

11. For a discussion on capital flight in several Latin-American countries see Dornbusch (1984). 
(8) $W=M P_{1}=B R^{1-B}$

where $R$ stands for the capital-labor ratio $(R=K / L)$. The solution of equations (6) - (8) determines the long-run values of the wage, the price of non-traded goods and the capital-labor ratio as a function of the exogenously given return on foreign investment $\left(\rho^{*}\right)$ :
(9) $\tilde{W}=\tilde{P}=\beta\left((1-\beta) / \rho^{*}\right]$
$(1-\beta) / \beta$
$\tilde{R}=\left[(1-\beta) / \rho^{*}\right]^{1 / \beta}$

where $\sim$ stands for the long-run value of the relevant variable. Note that the exogenously given rent on capital determines the long-run capital-labor ratio, which in turn determines the wage and thereby also the price of non-traded goods. Consequently, the wage depends negatively on the return on capital because a higher rent will reduce the capital-labor ratio.

To close the specification of the long-run equilibrium let us determine the size of each sector. Equations (1)-(4) imply that

$$
\text { (10) } P\left(\bar{L}-L_{z}\right)(1-g)=g L_{z}(R)^{1-\beta}
$$

Equation (10) determines for a given price $(P)$ and capital-labor ratio (R) the employment level in each sector (and thereby also the production level). Equation (9) determines the values of $P$ and $R$ as a function of the foreign rate of return $\rho^{*}$. Applying this information to (10) allows us to solve for the employment in each sector: 
(11) $L_{z}=\left[/[1+g /\{B(1-g)\}] ; L_{n}=[g /[B(1-g)+g]\right.$

A rise in the government share in the GNP $(g)$ or a drop in the labor share in the production of traded-goods ( $\beta$ ) will increase the non-traded sector.

\subsection{SHORT-RUN EQUILIBRIUM}

The short-run equilibrium is distinguished from the long-run by two considerations. First, the capital stock $(K)$ is exogenously given in the shortrun by past investment. Second, our formulation of the short-run production function is guided by the notion of the presence of time dependent labor reallocation costs. These costs may be related to a time consuming retooling process needed in order to absorb the added labor in the traded sector ${ }^{12}$. Labor is fully mobile in the long-run. In the short run, however, mobility of labor is costly and there are effective limits to the attainable reallocation. A key feature determining the cost of moving labor is the planning time that has been available before the move. For simplicity of exposition we consider here the extreme version of such a framework - the case where the cost of moving labor today is zero if the reallocation has been anticipated one period ahead, but is a concave function if the reallocation is unanticipated. A simple way to capture this notion is by postulating a time dependent production function in the traded-sector, where in the short-run output is given by

12. Notice that in the short-run, expansion of the traded-sector will require a change in the capital-labor ratio. Such a change may involve time consuming retooling. 


$$
Z_{t}=\left(L_{z, t}\right)^{\beta}\left(K_{t}\right)^{1-\beta}-\eta \frac{\left(L_{z, t}-E_{t-1}\left[L_{z, t}\right]\right)^{2}}{2 E_{t-1}\left[L_{z, t}\right]^{2}} B E_{t-1}\left[Z_{t}\right]
$$

where $Z_{t}$ is the output at time $t_{i} L_{z, t}$ is the labor employed in activity $Z$ at time $t_{i} E_{t-1}\left[L_{t}\right]$ and $E_{t-1}\left[Z_{t}\right]$ are the expected level of employment and output in activity $Z_{;}$where expectations are taken at the previous period $(t-1)$; and $\eta$ is a measure related to the magnitude of the contemporaneous costs of moving labor. We assume that an unanticipated reallocation of labor will entail adjustment costs that are quadratic in the magnitude of the unanticipated percentage change in employment in sector $Z^{13}$ Henceforth we denote $E_{t-1}\left[L_{z, t}\right]$ and $E_{t-1}\left[Z_{t}\right]$ by $-1 L_{z, t}$ and $-1 Z_{t}$. The formulation of (11) corresponds to the case where it takes one period to reach the long-run, where the planned and the actual employment are equal. This formulation can be extended to the case where adjustment is more gradual.

Suppose that we start from a long-run equilibrium at period $t-1$, and at period $t$ there occurs an unanticipated shock affecting wages ${ }^{14}$. Employment at time $t$ in the traded sector is determined so as to equate wages to the marginal product of labor:

13. Notice that $B E_{t-1}\left[Z_{t}\right]$ is the labor bill in the absence of shocks. Consequently, $\eta$ defines the magnitude of adjustment costs relative to the labor bill.

14. As we will demonstrate later, this shock may be the result of an unanticipated change in fiscal policy (i.e. a change in g). 
(13) $\quad W_{t}=\beta\left(L_{z, t}\right)^{\beta-1}\left(K_{t}\right)^{1-\beta}-\eta B-1 Z_{t} \frac{L_{z, t}-1 L_{z, t}}{\left(-1 L_{z, t}\right)^{2}}$

To simplify exposition it is useful to use lower-case letters to denote the percentage change in the variable of interest from the initial long-run equilibrium. Formally, for a variable $Y_{t}$ we define $y_{t}$ by:

$$
y_{t}=\left[Y_{t}--1 Y_{t}\right] /\left(Y_{t}\right)
$$

Applying this notation we can rewrite the condition for optimal short-run marginal changes in employment and output in the traded sector as

$$
\begin{aligned}
& \text { (14) } I_{z, t}=-w_{t} /(\eta+1-\beta) \\
& \text { (15) } z_{t}=B I_{z, t}=-w_{t} B /(\eta+1-\beta)
\end{aligned}
$$

A higher cost of labor adjustment $(\eta)$ and higher share of capital $(1-\beta)$ reduce the responsiveness of employment and output to changes in real wages.

Note that the RHS of equation (13) corresponds to the marginal product of labor, thus it must be positive. This requirement sets an upper limit for the feasible increase in the traded-sector employment in the short run, and this limit can be shown to depend negatively on the reallocation costs and positively on the labor share in the traded sector. For large $\eta$ it can be shown 
that (13) implies that $l_{z, t}<1 / \eta$. The presence of adjustment costs may have major implications (i.e., of a first order magnitude) regarding the feasible adjustment of quantities in the short-run, despite the fact that adjustment costst may have only marginal (i.e., of a second order magnitude) impact on profits. To exemplify this point suppose that the labor share $\beta$ is .75 , and let $\eta=50$. For such an economy the maximum feasible increase in the production of traded-goods in the short run does not exceed 1.5\%. This imposes a severe quantity restriction, despite the fact that the total magnitude of the adjustment costs do not exceed $.75 \%$ of the traded-goods output.

The transformation schedule of our economy is characterized in Figure 3. Starting from an initial long-run equilibrium at point $B$, the given stock of capital determines the location of the short-run transformation curve (curve $D C B A)$. At point $B$ the slope of the transformation curve corresponds to the long-run relative prices $(\tilde{P})$. Point $C$ corresponds to the maximum attainable increase in the output of traded-goods in the short-run ${ }^{15}$. The short-run transformation schedule is drawn for a given value of the cost of adjustment $(\eta)$. A lower adjustment cost is associated with less concavity of the short-run transformation curve and a shorter flat segment. In the absence of costs of adjustment we will observe a transformation schedule (like curve $D$ ' $B A^{\prime}$ ), where there is no limit to the feasible reallocation of labor in the short-run.

15. The employment in the traded sector at point $C$ corresponds to the level of labor where the marginal product in sector $Z$ equals zero (i.e. the $L$ where the RHS of (13) equals zero). 


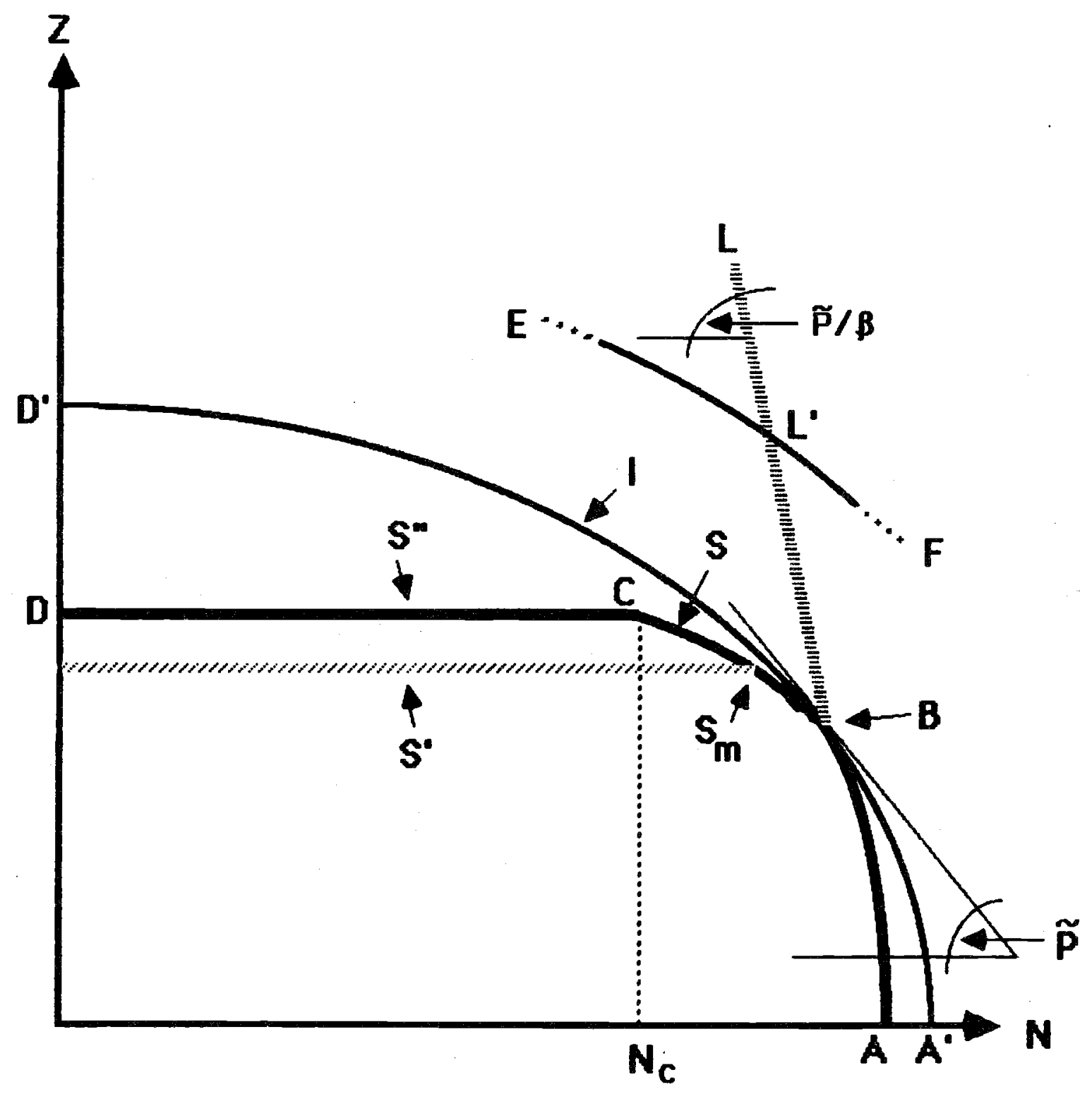

FIGURE 3 


\subsection{ADJUSTMENT TO FISCAL REFORM}

Consider an initial long-run equilibrium obtained for a given fiscal spending 8 . The characteristics of such an equilibrium are fully determined by equations (9) and (11). We evaluate in this section the adjustment to an unanticipated, permanent drop in fiscal activity (i.e. a permanent $d g<\theta$ ). In the short-run the economy adjusts by move leftward on the short-run transformation curve, towards point C. Note that equations (3) and (6) imply that

(16) $Z g /(1-g)=W N$

Consequently, for marginal changes we obtain (by logarithmic derivation) that:

$$
\text { (17) }(d g) /[g(1-g)]+B l_{z}=w+I_{n}
$$

Applying to (17) equations (4), (11), (14) and (15) we can derive the short-run changes in wages and relative prices:

$$
\text { (18) } w=p=(\alpha g) \frac{\eta+1-\beta}{(1-g)\{(\eta+1) g+\beta(1-g)\}}
$$

The drop in the government GNP share will release labor from the non-traded sector, causing a drop in wages and in the price of non-traded goods. The wage drop is larger for higher adjustment costs and for a lower share of labor in the 
production of traded-goods ${ }^{16}$. In terms of Figure 3, we will move to a new short-run equilibrium at point $S$.

The adjustment to point $S$ corresponds to the case of a marginal drop in fiscal activity. A drastic reduction in $g$ will lead to an equilibrium that approaches point $C$. This will correspond to the case where the drop in fiscal activity is substantial enough to approach the short-run employment capacity in the traded-sector. Note that equation (16) implies that

$$
\text { (16.) } W=g Z /[N(1-g)]
$$

This result implies that a drastic drop in fiscal demand will necessitate a corresponding drastic cut in wages. As $g \rightarrow 0$ we will approach point $C$, and equilibrium in the labor market requires $w \rightarrow 0$. The drastic drop in wages is needed to preserve full employment ${ }^{17}$.

In the presence of a minimum wage or any type of wage rigidity we will find that a drastic drop in the fiscal demand will lead us to a point like $S$ ', and will be associated with unemployment ${ }^{18}$. For example, if $w_{m}$ is the minimum wage, let $S_{m}$ be the point on the short-run transformation curve where the minimum wage is binding and let $g_{m}$ be the fiscal demand that brings us to that point. Any further drop in $g$ below $g_{m}$ will move us horizontally leftward, to a point like $S^{\text {'. }}$

16. Formally, equation (18) implies that sign $d w / d \eta=\operatorname{sign} d g$, and in the limit of $\eta \rightarrow \infty \quad d w=d g /[(1-g) g]$.

17. In terms of equation (16') as $g \rightarrow \theta$ the production will approach point $C$ (i.e., $(Z, N) \rightarrow\left(Z_{0}, N_{0}\right)$, where $\left(Z_{0}, N_{0}\right)$ is the vector of output at point $C$ ).

18. See Brecher (1974) for an analysis of the minimum wage in a model where all goods are traded. 
The short-run equilibrium is associated with an increase in rents above the external return. Equations (7), (14) and (18) imply that the change in domestic rents (denoted by $\rho$ ) is proportional to the drop in government demand:

$$
\begin{aligned}
& \text { (19) } \sigma \log \rho=\beta I_{2}=-W \beta /(\eta+1-\beta)= \\
& (-\sigma g) \frac{\beta}{(1-g)\{(\eta+1) g+\beta(1-g)\}}
\end{aligned}
$$

The increase in the rental income will generate investment in the traded sector, shifting the production frontier outward. The new long-run equilibrium will be obtained at a point like $\mathrm{L}$, corresponding to a higher production of traded-goods and lower production of non-traded. At the new equilibrium prices, wages and capital intensity will return to the level specified in equation (9). Note that we can apply equation (17) for the case where $w=\theta$ to derive the long-run changes in the production of the tradedgoods. Applying (4) and (11) to (17) we infer that

(20)

$$
\tilde{z}=\tilde{l}_{z}=\tilde{k}=(-d \tilde{g}) \frac{1}{[B(1-g)+g][1-g]}
$$

$$
\tilde{n}=\tilde{I}_{n}=-\tilde{l}_{z} \beta(1-g) / g=(-\sigma \tilde{g}) \frac{\beta}{|B(1-g)+g| g}
$$

The drop in the production of non-traded goods is proportional to the drop in the fiscal demand. The proportionality factor depends negatively on the labor 
share in the traded sector. We observe a magnification effect in that the percentage adjustment of traded output exceeds the percentage change in the government share in the economy. The straight line LB (Figure 3) traces the locus of the long-run equilibrium points obtained for various levels of fiscal demand ( $g$ ). Applying equations (1)-(2) to (9) we can infer that this locus is a straight line, whose slope is $\tilde{P} / \beta$. The exact location of the long-run equilibrium is dictated by the fiscal demand, and a lower 8 shifts the equilibrium upwards 19 .

19. Line LB is also the capital Rybczynski line. Note that a rise in $g$ will move the economy inward on the south-east extension of LB. 


\subsection{SOME POLICY IMPLICATIONS}

This discussion may have an important bearing regarding the choice of quantity versus wage policies by the fiscal authorities in an attempt to reduce the fiscal wage bill. Suppose that the government wishes to reduce the public sector wage bill as part of a fiscal reform program designed to reduce the fiscal deficit. One possible approach is for the fiscal authorities to initiate a wage policy: to determine a lower wage target and to adjust the fiscal activity (as summarized by the GNP share 8) and employment in the public sector to the wage target. An alternative approach is an employment policy: to determine a lower employment target in the public sector, to fire the excess labor (relative to the employment target) and to adjust the fiscal activity 8 to the new employment target. Let us apply our framework to contrast these two approaches.

If wages are flexible, a drop in the wage initiated by the government will move us towards point $\mathrm{C}$, but no matter what the magnitude of the drop we will not reach unemployment equilibrium. On the other hand, an active policy initiating a drop in employment in the public sector may lead to unemployment equilibrium at a point like S". For example, if the employment target in the public sector is below $N_{0}$, we will end up with very low wages and output at point $S "$. This observation is relevant especially in cases where we lack full information regarding the location of point C. Obviously, with full 
information regarding point $\mathrm{C}$ no policy maker will choose an employment target below $N_{0}$. In the absence of full information a wage policy is superior -with a wage policy we cannot go wrong, because at worst we will end up approaching point $C$. With an employment policy a bad choice of employment cut will lead the economy to an inefficient short-run equilibrium (like $S$ ") 20 .

\subsection{AN EXAMPLE}

To exemplify our discussion consider an economy characterized by the following information:

$$
\bar{L}=1, g=.25, \beta=.75, \rho^{*}=.1 \text {. }
$$

The long-run equilibrium of our economy can be solved by applying equations (1), (2) and (9), to yield:

$$
\tilde{N}=.31, \tilde{L}_{z}=.69 . \tilde{R}=3.39, \tilde{W}=1.02, \tilde{K}=2.34, \tilde{z}=.94
$$

Starting from the initial long-run equilibrium, suppose that there is an unanticipated, permanent drop in fiscal demand, reducing the GNP share of the government from .25 to. 2 . The new long-run equilibrium is characterized by

$$
\tilde{N}^{\prime}=.25, \tilde{L}_{z}^{\prime}=.75, \tilde{R}^{\prime}=3.39, \tilde{W}^{\prime}=1.02, \tilde{K}^{\prime}=2.54, \tilde{z}^{\prime}=1.02 .
$$

20. This implication applies also for the case where there is a minimum wage or wage rigidities. The only modification is that the rigidity places a lower-bound on the wage instrument. 
The long-run adjustment to a drop of $5 \%$ in the GNP share of the government will increase output in the traded sector by $8 \%$ and will require investment of $16 \%$ of the GNP.

We turn now to an evaluation of the short-run adjustment. Figure 4 plots the dependency of the adjustment of wages and traded output on the magnitude of the adjustment costs $(\eta)$. In the absence of adjustment costs a drop of $5 \%$ in the GNP share of the government will reduce the wage (and the price of non-traded goods) by $2 \%$ and the traded sector output will increase by 6\%. Larger values of the adjustment cost will increase the drop in wages and will reduce output changes. If $\eta=10$, wages (and the price of non-traded goods) will drop by $20 \%$ and output of traded goods will increase only by $1.5 \%$.

Our previous discussion and the present example suggest that fiscal deficits can be dealt with successfully by wage policies and by the corresponding adjustment in the government demand. These policies may have only marginal consequences on production of traded goods in the short run in the presence of high costs of adjustment. Over time we will observe two factors that will operate in favor of expansion of the traded sector. First, time will allow a successful reallocation of labor from the public to the private sector for a given stock of capital. In terms of Figure 4 this is equivalent to a drop in $\eta$, moving the economy leftward. This adjustment will be reflected in a gradual rise in wages and a corresponding expansion in the production of traded goods. In terms of Figure 3, a drop in the adjustment costs is associated with the flattening of the transformation curve, allowing the attainment of a point like I. The second adjustment will take place in the presence of investment attributed to the increase in rents resultant from the drop in wages. This process is time consuming, and is conditional on the credibility of 


\section{FIGURE 4}

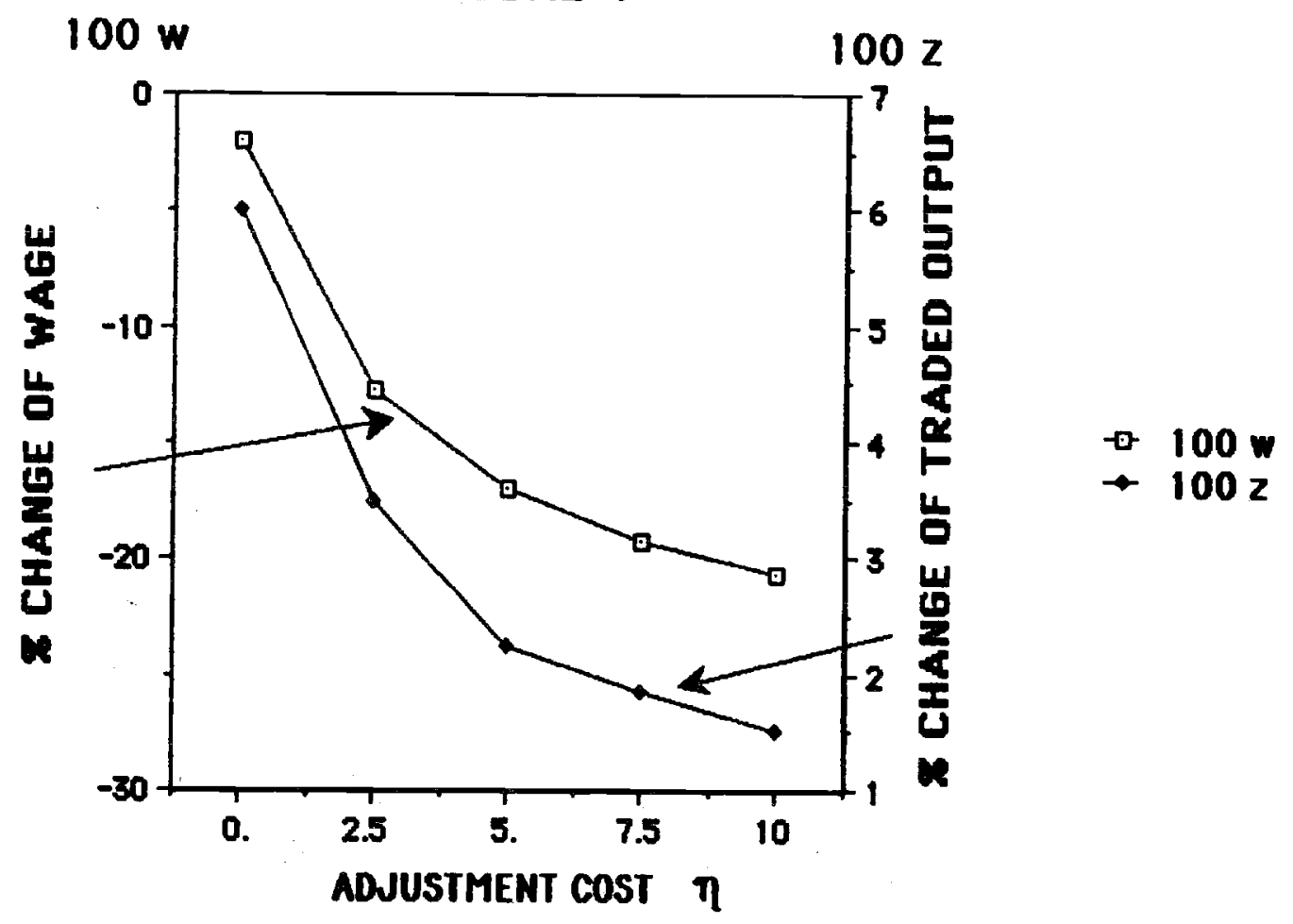


the fiscal reform. It will lead us over time to the long-run equilibrium, towards point $\mathrm{L}^{21}$.

\section{ADJUSTMENT TO FISCAL REFORM IN THE ABSENCE OF CREDIBILITY}

The previous discussion assumed that the reduction in the fiscal demand was viewed as permanent. This observation has a key importance for the behavior of domestic investors because they are looking forward in their investment decisions. As is evident from (19), the returns on productive capital are tied directly to the fiscal policy. Consequently, the fiscal reform's lack of credibility will be reflected directly in lower investment and in capital flight (relative to the case of a credible fiscal reform). Thus, it is constructive to conclude our discussion with an analysis of the importance of credibility in the adjustment process.

To demonstrate this point we turn now to the case where we start from an initial long-run equilibrium at $t-1$, and at time $t$ an unanticipated fiscal reform occurs (i.e. $d g<\theta$ at time $t$ ). Suppose that following the fiscal reform the private sector attaches only a probability $\psi$ to the sustainability of the fiscal reform for the long-run (i.e. $\psi$ is the probability that the drop in demand by $d g$ is permanent, and $1-\psi$ is the probability that the drop in demand is transitory). In such an environment the investment decision will internalize this uncertainty via the requirement that the expected yield on

21. One advantage of a wage policy may be in avoiding some of the unemployment during the transition. The lower unemployment may generate a positive externality by increasing the credibility of the fiscal stabilization, thereby encouraging private investment. 
investment in the traded sector equals the risk-free foreign yield (equation (5)). Applying equation 12 we can infer that equilibrium in the labor market requires

$$
w_{t+1}=\frac{k_{t+1}-I_{z, t+1}}{\eta+1-\beta}
$$

where lower-case letters measure the percentage change of the relevant variable relative to the initial long-run equilibrium at time $t-1$. Note that at time $t+1$ the stock of capital is given at the new level, thus we can apply the logic of our discussion regarding the short-run (section 2) to derive a condition for equilibrium in the goods market. Applying equations (11), (12) and (16) we can reduce this condition to

$$
d g_{t+1} /[g(1-g)]=w_{t+1}-(1-\beta) k_{t+1}-1_{z, t+1}
$$

Because at time $t+1$ the stock of capital is given, equations (21) and (22) can be solved simultaneously to determine the wage and employment at time $t+1$. The employment in the traded sector can be shown to be

$$
\text { (23) } l_{z, t+1}=-\frac{d g_{t+1} /[g(1-g)]+k_{t+1}(1-\beta-1 /\{\eta+1-\beta\})}{1 /\{\eta+1-\beta\}+\beta / g}
$$


Traded sector employment depends positively on the fiscal contraction. In the absence of short-run adjustment costs traded sector employment will go up with the accumulation of capital. Equation (12) implies that the change in the return to capital is given by

$$
d \log \rho_{t+1}=\beta\left[I_{z, t+1}-k_{t+1}\right]
$$

Notice that it is endogenously determined by the realized employment at time $t+1$ as given by equation (23). The employment, in turn, is determined by the realized fiscal shock. Thus, equations (23) and (24) determine the return at time $t+1$ as determined by past investment and the realized fiscal reform. The investment decision at time $t$ is forward-looking, and is calculated to equate the expected yield to the risk-free return. I.e., $k_{t+1}$ is chosen such that $E_{t}\left[\log \rho_{t+1}\right]=0$, where $E_{t}$ is the expectation operator, conditional on the information of time $t$. Applying this criterion to our case we infer from equations (23) and (24) that optimal investment at time $t$ is given by

(25)

$$
k=(-\Delta g) \frac{\psi}{[\beta(1-g)+g][1-g]} \text {; }
$$

alternatively, applying equation (20) we infer that

$$
k=\psi \tilde{k}
$$


where $\tilde{k}$ is the change in the stock of capital that will take place with complete credibility (given by equation 20). The credibility level has a major consequence on the long-run adjustment. At the extreme case, where the private sector views the fiscal reform as non-credible and transitory (i.e. $\psi=$ 0 ), no new private investment will occur, and the short-run equilibrium at time $t+1$ will occur on the same short-run transformation curve as at time $t$ (curve DCBA, Figure 3). A more credible regime (i.e a positive value of $\psi$ ) will be associated with positive investment, implying that the equilibrium at time $t+1$ will occur on curve EF, whose location is determined by the degree of credibility. A more credible regime will be associated with a greater outward shift of EF. At the limit of full credibility we will observe equilibrium at point $L$, where $E^{\prime} F^{\prime}$ is the short-run transformation schedule associated with it.

This discussion may have pessimistic implications regarding the success of a competitive equilibrium in generating sufficient new private investment. In the absence of full credibility we will observe a smaller investment. Furthermore, adjustment may be time consuming because the private sector will update its adjustment strategy according to a learning process regarding the credibility of the new regime. The absence of full credibility of stabilization programs may in fact be a common feature and not an exception. This observation stems from the fact that economies that are in need of stabilization have been brought to that need by policies that in most circumstances do not reflect credible and responsible policy making. Thus, the private sector may be fully rational in attaching initially low credibility to the stabilization scheme. If credibility is the binding constraint, there may be a potential role for subsidizing private investment, where the subsidy can be viewed as investment in reputation undertaken by the public sector. 


\section{REFERENCES}

Ben-Porat, Yoram. "The Entwined Growth of Population and Product: 1922 1982," appeared in Ben-Porat, Yoram (ed.) The Economy of Israel, Harvard Press, 1986.

Blejer Mario l. and Nissan Liviatan. "Stabilization Strategies in Argentina and Israel, 1985-1986," manuscript, IMF Fiscal Affairs Department, 1986.

Brecher,R. "Minimum Wage Rates and the Pure Theory of International Trade," Quarterly Journal of Economics, 88, 1974.

Bruno, Michael. "Generating A Sharp Disinflation: Israel 1985," NBER Working Paper No. 1822, 1986.

Corbo, Vittorio. "The Use of the Exchange Rate For stabllization Purpose, The Case of Chile," manuscript, The World Bank, 1985.

Dornbusch, Rudiger. "External Debt, Budget Deficits and Disequilibrium Exchange rates," NBER Working Paper No. 1336, 1984.

Dornbusch, Rudiger and Stanley Fischer. "Stopping Hyperinflations, Past and Present," NBER Working Paper No. 1810, 1986.

Edwards, Cox Alejandra. "Three Essays on Labor Markets in Developing Countries," Ph.D. dissertation, University of Chicago, 1984.

Edwards, Sebastian. "Stabilization with Liberalization: An Evaluation of Ten Years of Chile's Experiment with Free-Market Policies, 19731983," Economic Development and Cultural Change 34, 1985.

Foxley, Alejandro. "Towards A Free Market Economy, Chile 1974-1979," Journal of Development Economics 10, 1982.

Klinov Ruth. "Changes in the Industrial Structure," appeared in Ben-Porat, Yoram (ed.) The Economy of Israel, Harvard Press, 1986. 